Prospective

\section{Recent approach to incorporate tellurium in metal carbonyl cluster utilizing extrusion reaction}

\author{
Pradeep Mathur* and Ajeet Singh* \\ Discipline of Chemistry, School of Basic Sciences, Indian Institute of Technology Indore, \\ Simrol-453552, India
}

\section{Abstract}

The incorporation of tellurium into metal carbonyl using tellurium transfer/ extrusion reaction is presented in this work. The results bring one of the new ways to incorporate tellurium by transferring it from one molecule to another molecule, in comparison to the work so far where either insertion or extrusion reactions were shown. The reactions of $\mathrm{PhC}_{2} \mathrm{TeC}_{2} \mathrm{Ph}$ with the metal carbonyl cluster produced thermodynamically stable metal carbonyl tellurium clusters.

\section{More Information}

*Address for Correspondence: Ajeet Singh, Discipline of Chemistry, School of Basic Sciences, Indian Institute of Technology Indore, Simrol-453552, India, Tel: +91-9584417969; Email: director@iiti.ac.in; ajeetsinghm@gmail.com

Submitted: 08 November 2019

Approved: 25 November 2019

Published: 26 November 2019

How to cite this article: Mathur $P$, Singh A. Recent approach to incorporate tellurium in metal carbonyl cluster utilizing extrusion reaction. Ann Adv Chem. 2019; 3: 014-016.

DOI: dx.doi.org/10.29328/journal.aac. 1001020

Copyright: (c) 2019 Mathur P, et al. This is an open access article distributed under the Creative Commons Attribution License, which permits unrestricted use, distribution, and reproduction in any medium, provided the original work is properly cited.

\section{Check for updates}

OPEN ACCESS
Tellurium based compounds can be formed or modified by two types of reactions which are insertion and extrusion reactions [1]. With reference to the tellurium based reactions, the chemical reactions where tellurium, connected to two other atoms A and B, is lost to form an A-B bonded molecule are the extrusion reactions as shown in equation 1 .

$$
A-T e-B \stackrel{-T e}{\longrightarrow} A-B
$$

Insertion reactions are the reverse chemical process where tellurium gets inserted between $A$ and $B$, to form A-B molecule, as shown in equation 2 .

$$
A-B \stackrel{+T e}{\longrightarrow} A-T e-B
$$

We introduced one more equation here, in which a reaction of A-Te-B, with C-D forms A-B and C-Te-D by tellurium transfer reaction, as shown in equation 3 .

$$
A-T e-B+C-D \stackrel{-T e /+T e}{\longrightarrow} A-B+C-T e-D
$$

Initially, the synthesis of square-pyramidal triiron clusters $\left[\mathrm{Fe}_{3} \mathrm{Te}_{2}(\mathrm{CO})_{9}\right]$ (3) was carried by Hieber process by reacting $\mathrm{Na}_{2} \mathrm{TeO}_{3}(1)$ with $\mathrm{Fe}(\mathrm{CO})_{5}$ (2) in basic methanol solutions, followed by acidification (Scheme 1) [2].
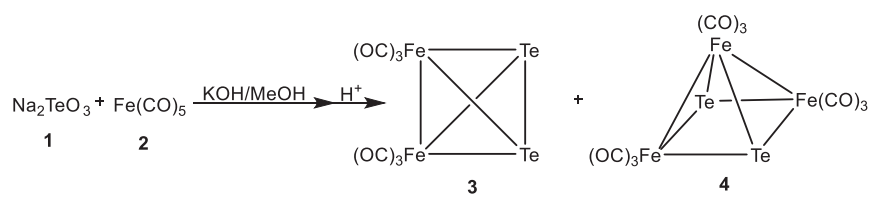

Later the method was modified, and the tellurium and $\mathrm{TeO}_{2}$ were directly used as the source for the synthesis of 16-transition metal carbonyl clusters. In the iron cluster system, $\mathrm{TeO}_{2}$ reaction with iron carbonyl in basic conditions yielded tetrahedral clusters $\left[\mathrm{TeFe}_{3}(\mathrm{CO})_{9}\right]^{2-}(6)$ (Scheme 2) [3].

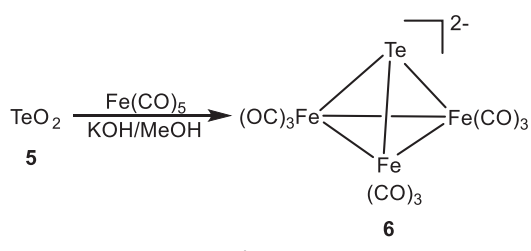

Another approach was to use the Zintl ions with metal carbonyls where reductive attack of polychalcogenides on the metal atoms followed by oxidative decarbonylation produced different high nuclearity carbonyl cluster. For example, $\left[\left(\mathrm{Te}_{2}\right)_{4} \mathrm{~W}_{6}(\mathrm{CO})_{18}\right]^{2-}(9)$ was formed by the reaction of $\mathrm{Na}_{2} \mathrm{Te}_{4}$ (7) and $\mathrm{W}(\mathrm{CO})_{6}(8)$ at $100{ }^{\circ} \mathrm{C}$ in DMF solution (Scheme 3). Similarly, $\mathrm{Fe}(\mathrm{CO})_{3}$ (4-butadiene) (10) reaction with $\mathrm{Na}_{2} \mathrm{Te}_{4}$ produced the butterfly $\left[(\mathrm{Te}) \mathrm{Te}_{2} \mathrm{Fe}_{2}(\mathrm{CO})_{6}\right]^{2-}$ (11) (Scheme 4) [4].

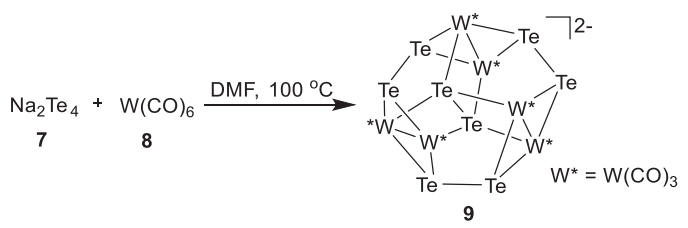




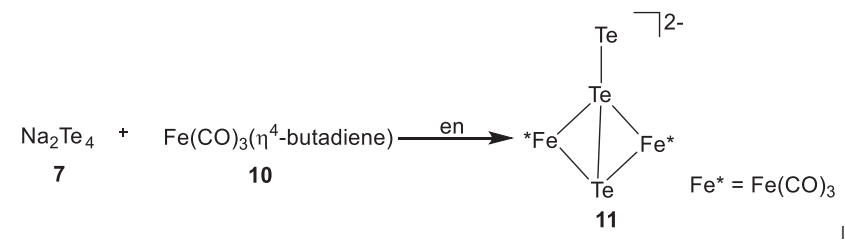

Scheme 4

Another approach showed that the reduction of the iron clusters say triiron telluride cluster $\left[\mathrm{Fe}_{3} \mathrm{Te}_{2}(\mathrm{CO})_{9}\right]$ (4) with 2 equiv. of $\mathrm{CoCp}_{2}(12)$ produced larger di- $\mathrm{Te}_{2} \mathrm{Fe}_{3}$ cluster which was $\left[\mathrm{Te}_{6} \mathrm{Fe}_{8}(\mathrm{CO})_{24}\right]^{2-}(13)$ (Scheme 5) $[5,6]$.

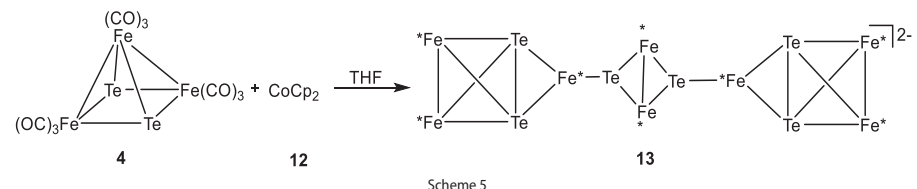

Other method includes hydro(solvo)thermal conditions by the use of which the oxidative decarbonylation of trinuclear iron cluster took place, for example, $\mathrm{Fe}_{3}(\mathrm{CO})_{12}$ (15) reaction with $\mathrm{Na}_{2} \mathrm{Te}_{2}$ (14) in $\mathrm{MeOH}$ at $110{ }^{\circ} \mathrm{C}$ or water at $130{ }^{\circ} \mathrm{C}$ gave the poly-ditelluride-iron clusters which were $\left[(\mathrm{TeMe})_{2}(\mathrm{Te})_{2}\left(\mathrm{Te}_{2}\right)_{2} \mathrm{Fe}_{4}(\mathrm{CO})_{8}\right]^{2-}(16)$ and $\left[\left(\mathrm{Te}_{2}\right)_{7} \mathrm{Fe}_{6}(\mathrm{CO})_{12}\right]^{2-}$ (17), respectively (Scheme 6) [7].

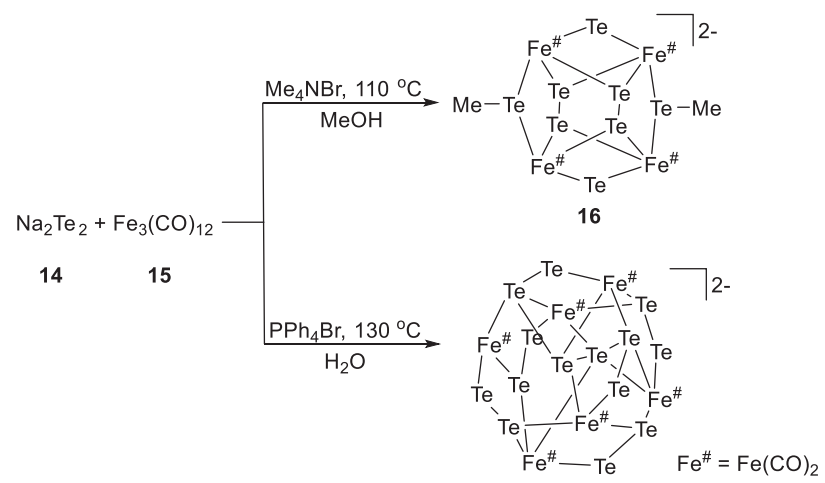

17

Scheme 6

The second type of reaction was extrusion reaction where the stepwise cleavage of carbon-tellurium bond took place with the extrusion, which produced different products along with the liberation of tellurium (Scheme 7) [8]. This extrusion can be brought about by thermal treatment or Laser-induced photolysis of 18 .

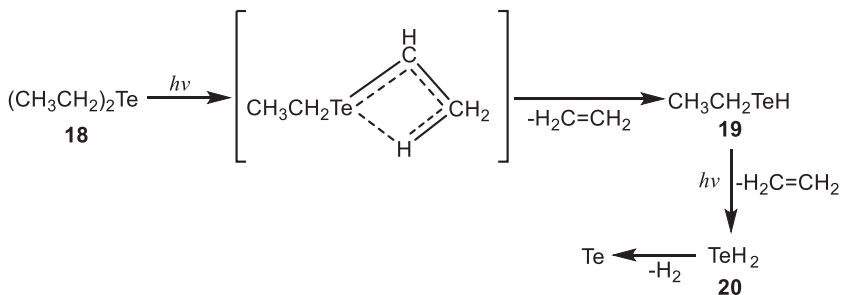

Scheme 7

Isotellurazoles (21) exclude tellurium after the addition of acetylenic dienophiles (22) to produce the polysubstituted pyridines (24) (Scheme 8) [9].

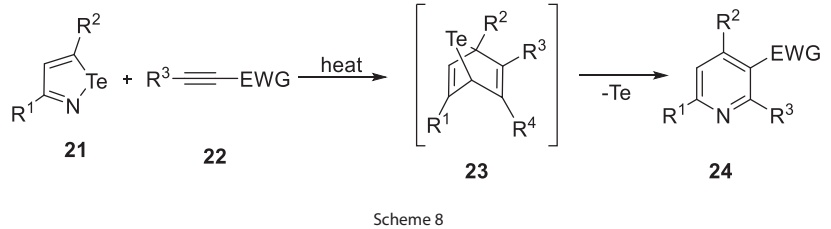

It was found that this reaction can only be favourable when at least one substituent on the acetylene was electron withdrawing [9]. Similarly, isotellurazole Te oxides (25) extrudes $\mathrm{TeO}$ and $\mathrm{Te}$ to form substituted pyridines (27) (Scheme 9) [9].

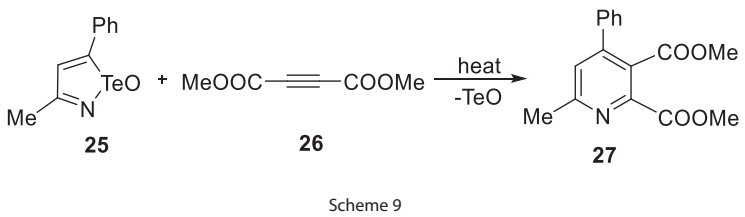

In another case, replacement of the tellurium atom by oxygen to form 29 was found in the peracid environment in the oxidation of a tellurophene (28) (Scheme 10) [10].

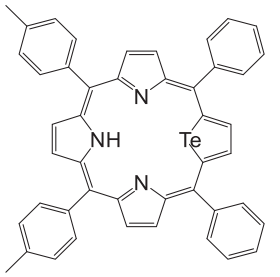

28

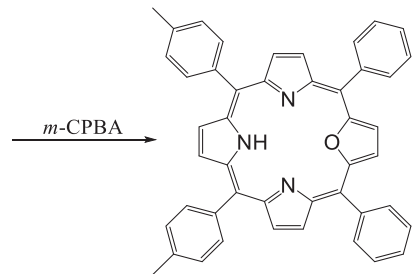

29
Other examples include the extrusion of tellurium from Bis-aryltelluro-cadmium (30) and Bis-aryltelluro-mercury compounds (Scheme 11) [11].

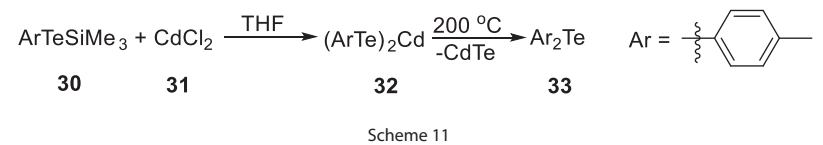

And, trinuclear metal carbonyl clusters on reaction with benzo[b]tellurophene (34) at higher temperatures afforded product with the expansion in the ring (35) (Scheme 12) [12].

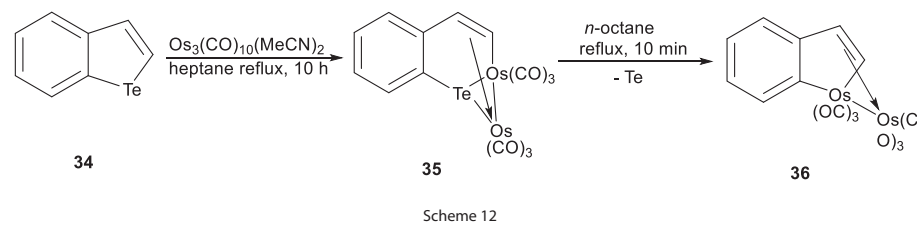

In the above examples, we did not notice that the extruded tellurium atom is utilised by the other reactant, or moieties present in the same reaction medium. We introduce a third type or another type of extrusion reaction called tellurium transfer/ extrusion reaction. To support this another kind of reaction, we found the examples where the extruded tellurium atom is utilised by the other simple metal carbonyl present in the reaction medium to produce the metal clusters 
incorporated with tellurium. Our previous paper presented an interesting $\mathrm{Ru}_{4} \mathrm{Te}_{2}(\mathrm{CO})_{12}$ cluster example which was synthesised, by the reaction of $\mathrm{Fe}_{3} \mathrm{Te}_{2}(\mathrm{CO})_{9}$ and $\mathrm{Ru}_{3}(\mathrm{CO})_{12}$ in benzene for $5 \mathrm{~h}$ at reflux (Scheme 13) [13].

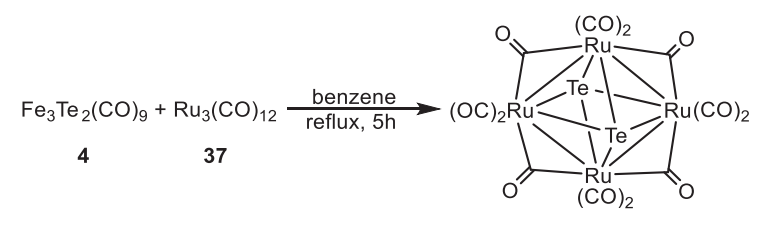

38

Scheme 13

Same $\mathrm{Ru}_{4} \mathrm{Te}_{2}(\mathrm{CO})_{12}$ product can be obtained in $40 \%$ yield (based on $\mathrm{Ru}_{3}(\mathrm{CO})_{12}$ ), by the reaction of $\mathrm{PhC}_{2} \mathrm{TeC}_{2} \mathrm{Ph}$ with $\mathrm{Ru}_{3}(\mathrm{CO})_{12}$ along with $\mathrm{PhC}_{2} \mathrm{C}_{2} \mathrm{Ph}$ (76\% yield), which shows the transfer of tellurium from $\mathrm{PhC}_{2} \mathrm{TeC}_{2} \mathrm{Ph}$ to $\mathrm{Ru}_{4} \mathrm{Te}_{2}(\mathrm{CO})_{12}$ (Scheme 14).

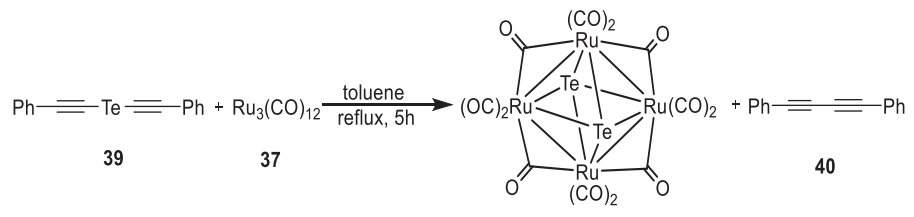

38

Scheme 14

Further, we performed other reaction of $\mathrm{Fe}_{2}(\mathrm{CO})_{9}$ with $\mathrm{PhC}_{2} \mathrm{TeC}_{2} \mathrm{Ph}$ in thermal reaction conditions and found the earlier synthesised stable $\mathrm{Fe}_{3} \mathrm{Te}_{2}(\mathrm{CO})_{9}(4)$ cluster [2] as the product $\left(45 \%\right.$ yield based on $\mathrm{Fe}_{2}(\mathrm{CO})_{9}$ ) with the liberation of $\mathrm{PhC}_{2} \mathrm{C}_{2} \mathrm{Ph}$ (85\% yield) (Scheme 15).

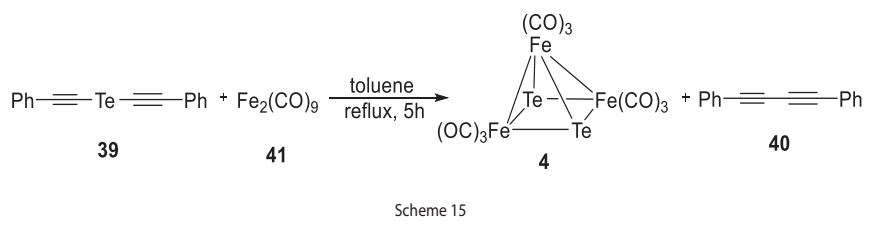

\section{Conclusion}

We believe and propose that the reaction of $\mathrm{PhC}_{2} \mathrm{TeC}_{2} \mathrm{Ph}$ with the metal carbonyl cluster will produce the more thermodynamically stable metal carbonyl tellurium clusters in thermal reaction conditions [14].

\section{Acknowledgement}

PM gratefully acknowledges the JC Bose National Fellowship. AS acknowledges MHRD, New Delhi, India and IIT Indore.

\section{Electronic Supplementary Information}

\section{References}

1. In PATAl'S Chemistry of Functional Groups. 2009.

2. Hieber W, Gruber J. Zur Kenntnis der Eisencarbonylchalkogenide. Z Anorg Allg Chem. 1958: 296: 91-103

3. Bachman RE, Whitmire $\mathrm{KH}$. The Synthesis and Characterization of a Series of Iron Carbonyl Clusters Containing Selenium and Tellurium. Inorg Chem. 1994; 33: 2527-2533.

4. Eichhorn BW, Haushalter RC, Merola JS. Synthesis, structure, and properties of $\mathrm{Fe}_{2} \mathrm{Te}_{3}(\mathrm{CO})_{6}{ }^{2-}$ containing the unusual $\mu^{2}-\eta^{1}-\mathrm{Te}_{2}{ }^{2-}$ ligand. Inorg Chem. 1990; 29: 728-731.

5. Shieh M, Chen PF, Tsai YC, Shieh MH, Peng SM, et al. Facile Syntheses and Transformations of a Series of Tellurium-Iron Carbonyl Clusters: Crystal Structures of $\left[\mathrm{PhCH}_{2} \mathrm{NMe}_{3}\right]_{2}\left[\mathrm{Te}_{6} \mathrm{Fe}_{8}(\mathrm{CO})_{24}\right], \mathrm{Fe}_{2}(\mathrm{CO})_{6}\left(\mu-\mathrm{TeCHCl}_{2}\right)_{2}$, and $\mathrm{Fe}_{2}(\mathrm{CO})_{6}(\mu-\mathrm{TeCHPhTe})$. Inorg Chem. 1995; 34: 2251-2254.

6. Shieh, M. Recent Developments of Tellurium- and Selenium-Containing Iron Carbonyl Clusters. J Cluster Sci. 1999; 10: 3-36.

7. Das BK, Kanatzidis MG. Solvothermal synthesis and structure of iron tellurido carbonyl clusters. Polyhedron. 2000; 19: 1995-2002.

8. Lau P, Braunwarth $\mathrm{H}$, Huttner G, Guenauer D, Evertz K, et al. Oxidative transformation of $\left[\mathrm{RCp}(\mathrm{CO})_{2} \mathrm{MnSR}\right]$.bul. radicals into manganese inidene compounds $\left[\mathrm{RCp}(\mathrm{CO})_{2} \mathrm{Mn}\right]_{2} \mathrm{SR}^{+}$. Organometallics. 1991; 10: 3861-3873.

9. Eikens W, Jäger S, Jones PG, Thöne C. Organometallic selenolates. Part 2. A new synthesis of dimeric (selenolato) tetracarbonylmanganese $(I)$ complexes. Crystal structures of $\left[\mathrm{Mn}(\mathrm{CO}){ }_{4} \mathrm{SeR}\right]_{2} ; \mathrm{R}=\mathrm{CH}_{2} \mathrm{Ph}, \mathrm{C}(\mathrm{O}) \mathrm{Ph}$ and $\mathrm{CO}_{2}$ Me. J Organomet Chem. 1996; 511: 67-75.

10. Latos-Grażyński L, Pacholska E, Chmielewski PJ, Olmstead MM, Balch AL. Alteration of the Reactivity of a Tellurophene Within a Core-Modified Porphyrin Environment: Synthesis and Oxidation of 21-Telluraporphyrin. Angew Chem Int Ed Engl. 1995; 34: 2252-2254.

11. Steigerwald ML, Sprinkle CR. Organometallic synthesis of II-VI semiconductors. 1. Formation and decomposition of bis(organotelluro) mercury and bis(organotelluro) cadmium compounds. J Am Chem Soc. 1987; 109: 7200-7201.

12. Arce AJ, Karam A, De Sanctis Y, Machado R, Capparelli MV, et al. Ring opening and extrusion of tellurium atoms in the reaction of benzo[b] tellurophene with trinuclear iron, ruthenium and osmium clusters: X-ray crystal structures of $\left[\mathrm{Os}_{2}\left(\mu-\mathrm{C}_{8} \mathrm{H}_{6} \mathrm{Te}\right)(\mathrm{CO})_{10}\right], \quad\left[\mathrm{Os}_{4}\left(\mu-\mathrm{C}_{8} \mathrm{H}_{4}\right)\left(\mu^{3}-\right.\right.$ $\left.\mathrm{Te})\left(\mathrm{CO}_{11}\right], \quad\left[\mathrm{Ru}\left(\mu-\mathrm{C}_{8} \mathrm{H}_{6} \mathrm{Te}\right)(\mathrm{CO})_{6}\right)\right],\left[\mathrm{Ru}_{4}\left(\mu^{3}-\mathrm{Te}\right)\left(\mu-\mathrm{C}_{8} \mathrm{H}_{6}\right)(\mathrm{CO})_{11}\right]$ and $\left[\mathrm{Fe}_{2}\right)$ $\mu-\mathrm{C}_{8} \mathrm{H}_{6} \mathrm{Te}(\mathrm{CO})_{6}$ ]. Inorg Chim Acta. 1997; 254: 119-130.

13. Mathur $\mathrm{P}$, Thimmappa BHS. The synthesis and characterisation of the novel cluster, $\mathrm{Ru}_{4} \mathrm{Te}_{2}(\mathrm{CO})_{12}$. J Organomet Chem. 1989; 365: 363-366.

14. Singh $A$, Mathur $P$. Incorporation of tellurium into metal carbonyl through $\mathrm{PhC}_{2} \mathrm{TeC}_{2} \mathrm{Ph}$. In preparation. 